1984

\title{
The Ultrastructure of Cell Division in the Marine Red Alga Lomentaria baileyana
}

\author{
Elizabeth Carpenter Davis \\ College of William \& Mary - Arts \& Sciences
}

Follow this and additional works at: https://scholarworks.wm.edu/etd

Part of the Cell Biology Commons

\section{Recommended Citation}

Davis, Elizabeth Carpenter, "The Ultrastructure of Cell Division in the Marine Red Alga Lomentaria baileyana" (1984). Dissertations, Theses, and Masters Projects. Paper 1539625243.

https://dx.doi.org/doi:10.21220/s2-b5yg-5562 


\title{
THE ULTRASTRUCTURE OF CELL DIVISION IN THE MARINE RED ALGA \\ LOMENTARIA BAILEYANA
}

\author{
A Thesis \\ Presented to \\ The Faculty of the Department of Biology \\ The College of William and Mary in Virginia \\ In Partial Fulfillment \\ Of the Requirements for the Degree of \\ Master of Arts
}

by
Elizabeth Carpenter Davis
1984


ProQuest Number: 10626470

All rights reserved

INFORMATION TO ALL USERS

The quality of this reproduction is dependent upon the quality of the copy submitted.

In the unlikely event that the author did not send a complete manuscript and there are missing pages, these will be noted. Also, if material had to be removed, a note will indicate the deletion.

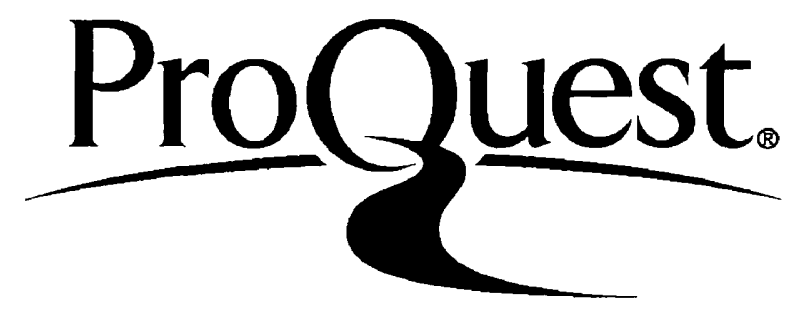

ProQuest 10626470

Published by ProQuest LLC (2017). Copyright of the Dissertation is held by the Author.

All rights reserved.

This work is protected against unauthorized copying under Title 17, United States Code Microform Edition (c) ProQuest LLC.

ProQuest LLC.

789 East Eisenhower Parkway

P.O. Box 1346

Ann Arbor, Ml 48106 - 1346 
APPROVAL SHEET

This thesis is submitted in partial fulfillment of the requirements for the degree of Master of Arts

$\frac{\text { Elyabuth C Ours }}{\text { Elizabeth Carpenter Davis }}$

Approved, December 1984
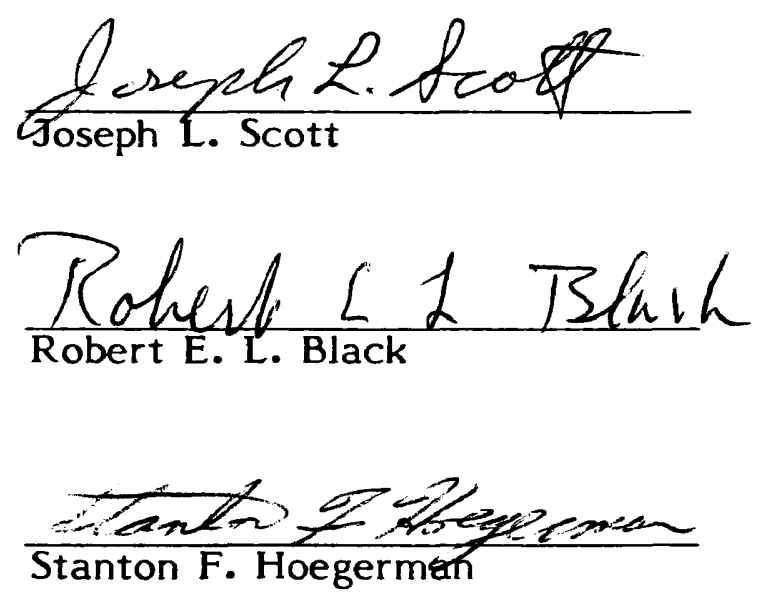

ii 


\section{TABLE OF CONTENTS}

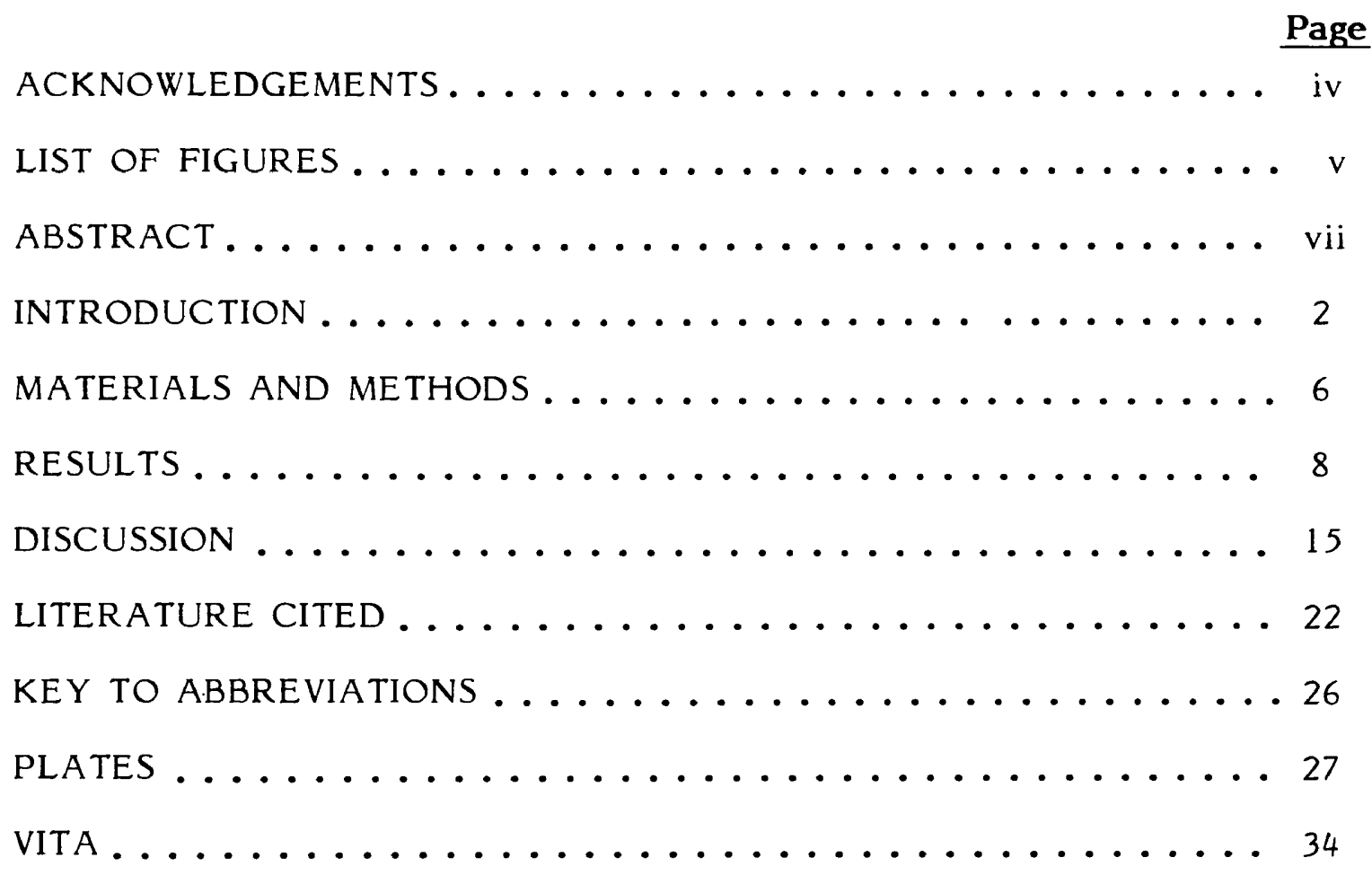




\section{ACKNOWLEDGEMENTS}

I would like to express my sincere appreciation to Dr. Joseph $L$. Scott for his guidance, enthusiasm and friendship during the course of the investigation. I wish to recognize Dr. Stanton Hoegerman and Dr. Robert E. L. Black for the critical reading of this manuscript. I am also grateful to Jewel P. Thomas and Bill D. Saunders for their technical instruction and support. 


\section{LIST OF FIGURES}

Figure $\quad \underline{\text { Page }}$

1. Light micrograph of longitudinal section through branch tip of Lomentaria baileyana ........... 27

2. Electron micrograph of central most tip region........ 27

3-4. Consecutive sections of early prophase nucleus with migrating polar rings.............. 27

5. Longitudinal section of a prophase polar ring . . . . . . . 27

6. Transverse section of a prophase polar ring . . . . . . . 27

7. Prophase nucleus with migrating polar rings ......... 28

8. Early prometaphase oval nucleus .............. 28

9-12. Consecutive sections of a prometaphase division pole with nuclear envelope invaginations .......... 29

13-14. Consecutive sections of a prometaphase nucleus where the invagination has ruptured ........... 29

15. Mid prometaphase pole with a ruptured invagination to one side of the polar ring ......... 30

16. Mid prometaphase pole with a ruptured invagination to one side of a tangentially

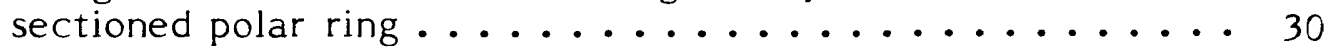

17. Elongated late prometaphase nucleus ........... 30

18. Elongated late prometaphase nucleus .......... 30

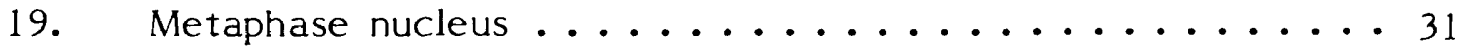

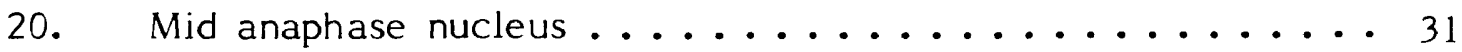

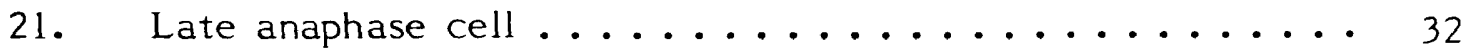

22. Polar region of a late anaphase nucleus .................... 32

23. Late telophase cell with remnants of the inter-

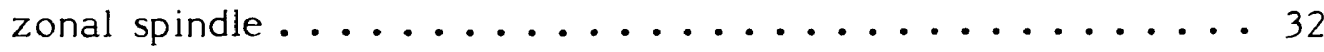


$\frac{\text { Figure }}{24 .}$ Late telophase cell with large central vacuole....... $\frac{\text { Page }}{33}$

25. Late telophase cell, large central vacuole not seen...... 33

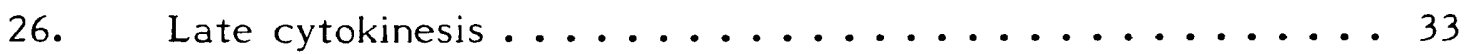

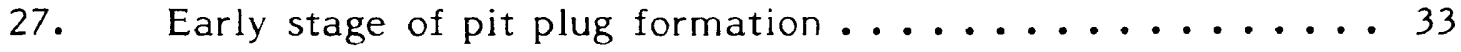




\begin{abstract}
Mitosis in the marine red alga Lomentaria baileyana (Rhodymenialies, Rhodophyta) was studied with the electron microscope. Nucleus associated organelles known as polar rings (PRs) migrate to establish the division poles at prophase. At prometaphase, shallow invaginations in the nuclear envelope (NE) form on two sides of each PR and soon rupture. The gaps that are consequently formed contain several small fragments of NE. A larger region of NE remains intact between the two gaps. By metaphase several cisternae of perinuclear endoplasmic reticulum (PER) have enclosed most of the nucleus but remain absent from the polar regions. The nucleolus disperses partially and a typical metaphase plate of chromosomes is formed. Each PR has disjoined into separate proximal and distal portions. MTs converge widely on all regions of the polar area, but do not extend into the cytoplasm. Some MTs end near or at the chromosomes while others extend slightly farther past the chromosomes or diagonally to the NE. As chromosomes move to opposite poles at anaphase, they are accompanied by nucleolar material. An interzonal midpiece (IZM) is created as the pole to pole distance increases and the $\mathrm{NE}$ remains intact except for the polar gaps. Following detachment from the IZM, the daughter nuclei are separated by a large central vacuole as a cleavage furrow develops and eventually constricts to form two cells. It is suggested that mitosis in Lomentaria represents an evolutionary intermediate between that seen in the higher and lower groups of red algae. This conclusion is in agreement with conventional morphological and light microscopic criteria used to place Lomentaria in the Rhodymeniales, which is considered to be the second most advanced order in the Rhodophyta.
\end{abstract}


THE ULTRASTRUCTURE OF CELL DIVISION

IN THE MARINE RED ALGA

LOMENTARIA BAILEYANA 


\section{INTRODUCTION}

Mitosis is a fundamental process of all eukaryotic cells and has been the subject of much interest since the invention of the light microscope. The introduction of the electron microscope (EM) and the perfection of EM techniques have opened an entirely new approach to research in this area. In addition to biochemical and physiological analyses, numerous EM studies are now contributing to knowledge of the structure and function of the motitic process (to cite a few: Bajer 1973, Bajer and Mole-Bajer 1972, Fuge 1974, Heath 1981, Hepler 1980, Inoue and Ritter 1975, Jackson and Doyle 1982, Luykx 1970, McDonald et al. 1977, Pickett-Heaps 1969, 1975b, 1978, Stewart and Mattox 1975).

Although mitosis remains essentially uniform among higher plants and animals, lower eukaryotes show an abundance of variation in the basic process. Electron microscopic studies of mitosis have aided in the phylogeny and systematics of many lower eukaryotes (summary articles: Heath 1980a, Fuller 1976, Kubai 1975, 1978, Leedale 1970, Pickett-Heaps 1974 , 1975a). Some of these studies have brought about changes in the systematics of green algae and in the interpretation of their relationship to higher plants (Pickett-Heaps 1975a, Stewart and Mattox 1975) and have also helped reevaluate fungal taxonomy (Fuller 1976, Heath 1978).

Although the contributions of electron microscope studies of cell division to phylogeny and taxonomy are numerous, it is necessary to recognize the limitations of these studies. In specific, the use of ultrastructural 
details of mitosis as a phylogenetic indicator becomes difficult when one must decide which equally efficient mitotic apparatus is more primitive. Moreover, it is not uncommon for an advanced organism to have what is considered a primitive mitotic apparatus or a primitive organism to have an advanced apparatus (Oakley 1978). Better applied as a taxonomic criterion, ultrastructual studies of mitosis are further limited by technical problems inherent to electron microscopy. It is a slow, laborious procedure to prepare and section specimens for the electron microscope and one has to interpret three dimensional structures from thin, two dimensional tissue slices. The loss or relocation of material within a cell and the addition of artifactual material often interfere with the ability to draw conclusive results. Morphological identification of cellular compounds with the electron microscope must often be followed by indirect cytological or biochemical analyses for verification (Heath 1981). Despite these important limitations, carefully interpreted ultrastructural studies of mitosis will continue to provide much needed information for phylogenetic and taxonomic purposes.

Research of this nature on red algae has begun only recently. The poor EM fixation usually obtained with red algae, their inaccessibility as predominantly marine plants unable to thrive easily in laboratory conditions, and the extreme difficulty in identifying the brief daily time perioids when cells divide are the main reasons for this delay. While progress is slow and "EM has been of less use in red algal systematics than in similar studies of any other algal group" (Duckett and Peel 1978), more recently the wealth of information accumulated from EM research is changing this.

The division Rhodophyta has two classes, The Bangiophyceae and 
the Florideophyceae. The former is predominantly composed of unicellular and simple multicellular plants which lack any type of sexual reproduction, whereas the plants in the latter class are multicellular with complex sexual life histories. Traditional ordinal classification within the Florideophyceae has been based on variations of the morphological events that occur immediately before and after fertilization on the female plant. In cases where female plants are lacking, or where an entire order shows exceptional uniformity in this criterion, other factors such as differences in vegetative morphology, spore production and life histories have been employed (Bold and Wynne 1978, Dixon 1973). In recent years ultrastructural investigations have revealed several possible features that may assist in clarifying the systematics of this ancient plant group. Comparative studies on chloroplast ultrastructure (summary article: Hara and Chihara 1974), dictyosome structure and association (Duckett and Peel 1978, Scott 1984), and pit plug morphology (Pueschel 1980, Pueschel and Cole 1982) have been done.

The focus in our laboratory has been on the use of details of cell division as criteria to be considered in red algal taxonomy (Broadwater and Scott in prep., Phillips and Scott 1981, Schornstein and Scott 1982, Scott 1983, Scott et al. 1980).

Within the Florideophyceae, mitosis has been investigated in a plant of the simplest order, the Nemaliales (Scott 1983) and in plants of the most advanced order, the Ceramiales (Charleston 1984, Dave and Godward 1982, MacDonald 1972, Phillips and Scott 1981, Scott et al. 1980). The object of this study, Lomentaria baileyana, is in the order Rhodymeniales, which has three families: the Rhodymeniaceae, the Champiaceae and the Lomentariaceae. Champia parvula and Lomentaria baileyana, from the latter two families respectively, are found in the coastal waters off 
the Eastern Shore of Virginia and are easily accessible. Because the Rhodymeniales is also considered an advanced order of the Floridiophyceae, it is desirable to see if mitosis within this order is similar to that already studied in the Ceramiales. Although both Champia parvula and Lomen$\underline{\text { taria }}$ baileyana were studied, only Lomentaria fixed well enough to be studied in detail with the electron microscope. 


\section{MATERIALS AND METHODS}

Sterile specimens of Lomentaria baileyana were collected in channels near Wachapreague Inlet, VA by trawling from a boat in the shallow coastal waters in early autumn. They were immediately transported to the laboratory and cultured in equal volumes of von Stosch's culture medium (von Stosch 1964) and filtered sea water. Specimens were maintained in a culture room on a shaker table under a set photoperiod (14L:10D) for three days at $22^{\circ} \mathrm{C}$. On the fourth day, $2 \mathrm{hrs}$. into the light period, the specimens were fixed for 2 hrs. in a solution of $2 \%$ glutaraldehyde in $0.1 \mathrm{M}$ phosphate buffer $(\mathrm{pH}$ 6.6) and $0.25 \mathrm{M}$ sucrose. Specimens, after several rinses in $0.1 \mathrm{M}$ buffer with $0.25 \mathrm{M}$ sucrose, were postfixed in $1 \%$ $\mathrm{OsO}_{4}$ in the same buffer for 1-2 hrs. A 5 min. dehydration in $50 \%$ acetone was followed by an overnight stay in a $2 \%$ uranyl acetate-70\% acetone solution at $4^{\circ} \mathrm{C}$. Dehydration was then continued in $70 \%$, $90 \%$ and three $100 \%$ acetone rinses. Infiltration with an increasing ratio of Embed 812 resin to $100 \%$ acetone was carried out over an hr. The alga was left in pure resin for $24 \mathrm{hrs}$. before embedding the tip regions of the plant.

The specimens were kept three days in an oven at $60^{\circ} \mathrm{C}$ for polymerization of the resin.

Thin sections were made with a Dupont diamond knife on a Sorvall MT 2-B ultramicrotome. Sections were collected on one-hole grids, stained in lead citrate and transferred to formvar coated one-hole grids. They were photographed with a Zeiss EM 9S-2 electron microscope. Thick 
sections $(0.5 \mathrm{um})$ were also made with a diamond knife and stained with toluidine blue for photography with a Zeiss Photomicroscope II using bright field optics. Whole live specimens were photographed with a Wild M400 Photomicroscope. 


\section{RESULTS}

\section{Light Microscope Observations}

Lomentaria baileyana is a hollow, tubular alga that can grow to 10 $\mathrm{cm}$ in length. It has an irregular branching pattern and exhibits multiaxial growth. Light microscope observations of longitudinally sectioned tip regions (Fig. 1) reveal chains of greatly elongated cells that border a central cavity. These filaments originate from apical cells of unlimited growth at the tip region. Bordering the outside of these chains are other filaments of limited growth that form the cortical region. Elongated axial cells and older cortical cells are multinucleate and contain large central vacuoles. Apical cells and adjacent young cortical cells lack large vacuoles, and have a single central nucleus 3-5 um in diameter (Fig. 2). Division was observed in these two types of small eliptically shaped cells. Cells in various stages of mitosis were found in Lomentaria at a greater frequency relative to the amount of time spent searching than in any red alga previously studied in this laboratory.

\section{Electron Microscope Observations}

Interphase and Prophase

This is the first ultrastructural study done on the genus Lomentaria using modern fixation techniques, (see Bouck, 1962, for a general ultrastructural study which utilized permanganate fixation). Mitotically quiescent axial filament cells have a large central vacuole and are from two 
to four times longer than the apical cells. Two or three small nuclei and chloroplasts are prominent within the band of cytoplasm at the cell perimeter. In potentially mitotic apical and young cortical cells, the nucleus consists of a dispersed chromatin network with a large nucleolus. Two nucleus associated organelles (NAOs), similar in morphology to the polar rings (PRs) described in Apoglossum (Dave and Godward (1982), Membranoptera (McDonald 1972), Polysiphonia (Scott et al. 1980), and Dasya (Phillips and Scott 1981), are present in both quiescent and mitotically active cells. Although a pair of polar rings was never seen in potentially mitotic interphase cells as reported by Scott et al. (1980), they were found in various stages of migration at the onset of prophase (Figs. 3, 4, 7). PRs are short, hollow electron dense cylinders, $120-140 \mathrm{~nm}$ in diameter and 40-60 $\mathrm{nm}$ in height. They are composed of closely associated proximal and distal portions, and are always found with their longitudinal axes oriented perpendicular to the nuclear envelope (NE), (Fig. 5). A small ribosome-free zone of exclusion surrounds the PRs as they migrate to establish the division poles. Microtubules (MTs) can be seen extending from the zone into the cytoplasm and along the NE. Directly beneath each PR is a nuclear envelope protrusion (NEP), which may contain a small amount of heterochromatin (Figs. 5, 7). The regions of NE to either side of the $P R$ are dense with nuclear pores, whereas the NEP remains pore-free. Transverse sections of the $P R$ reveal a circular membranous structure inside (Fig. 6). When viewed in longitudinal sections, the projection through the PRs appears to be an extension of the outer NE membrane (Figs. 5, 7). In some sections, a narrow tubular extension of smooth endoplasmic reticulum appears connected to this projection. Once the polar rings have completed their migration establishing the division axis, 
the zones of exclusion enlarge. Chromatin begins to condense more noticeably, while the nucleolus remains distinct.

Prometaphase

During late prophase-early prometaphase, the nucleus changes from a spherical to a more oval shape. The NE becomes flattened at the poles and the zones of exclusion enlarge to encompass this region (Fig. 8). Nuclear pores increase in density at the sides of the NEP that subtends each PR. Chromatin continues to condense as the nucleolus starts to disperse. One or two cisternae of perinuclear rough endoplasmic reticulum (PER) have gathered near the nucleus but do not surround the polar regions. As prometaphase proceeds, invaginations or pockets of the NE that are largely pore-free, form on opposite sides of each polar ring. Figures 9-12 show serial sections of the only nucleus found at this stage of prometaphase. Adjacent sections of one pocket region in another nucleus (Figs. 13, 14) illustrate that pockets, in which MTs were never observed, do not penetrate deeply before rupturing. The two nuclei in Figures 15 and 16 show one of the two gaps, with the associated PR now separated slightly into proximal and distal portions. At this time the chromosomes, apparently fully condensed, are randomly distributed throughout the nucleus. Although distinct kinetochores are not observed routinely here or at any subsequent stage of mitosis (see however Fig. 20), they are assumed present, but not well preserved by this fixation process.

Four cells were seen in late prometaphase. The nucleus has become much elongated and the gaps have widened as numerous MTs are seen within the nucleus. At the gap edges, some portions of the NE from the ruptured pockets are still seen inside the nucleoplasm, while at least 
one prominent NE fragment remains in the gap midregion. The nature of the PRs at this time is undetermined. Chromosomes begin to congress toward the nuclear midregion, and the nucleolus, which appears pushed against the $\mathrm{NE}$, has dispersed further but remains discernable. Mitochondria begin to collect close to the poles while small vacuoles gather in the cytoplasm a short distance from the nucleus (Figs. 17, 18).

\section{Metaphase}

Figure 19 shows the chromosomes assembled on a typical equatorial plate. What had been an elongated nucleus during late prometaphase has now developed a pronounced bulge in the middle which accommodates the chromosomes, so that the pole to pole distance has become shorter than the distance across the metaphase plate. The partly dispersed nucleolus is often seen pushed against the $\mathrm{NE}$ in the plate region. A total of 22 metaphase nuclei were observed, about half of which were at least partially serially sectioned. However, only two metaphase nuclei with PRs were found (not shown because of lead contamination). One was cut tangentially in such a way to reveal the proximal and distal portions of the PR positioned above a central fragment of NE. The distance between the portions was greater than that seen in prometaphase (Figs. 15, 16) and appears similar to that reported in Polysiphonia and Dasya (Phillips and Scott 1981, Scott et al. 1980). One or two fragments of NE can be seen at the polar regions in some planes of sections, whereas in adjacent sections of the same cell, the poles appear as a large gap devoid of any obvious NE fragments. The NE fragments in the nucleoplasm at prometaphase are no longer present. MTs converge widely on all regions of the polar area, but do not extend into the cytoplasm. Some MTs end 
near or at the chromosomes while others extend slightly farther past the chromosomes or digaonally to the NE. Mitochondria, appearing to provide a boundary between nucleoplasm and cytoplasm, closely line the poles. Vacuole formation continues and two to three cisternae of PER envelop the NE at metaphase, although at the poles this close juxtaposition is lost and the PER extends into the cytoplasm.

\section{Anaphase-Telophase-Cytokinesis}

As the chromosomes begin moving to opposite poles at the onset of anaphase, fragments of the nucleolus are seen accompanying them (Fig. 20). The chromosome to pole movement appears to occur slightly before most of the pole to pole separation. A conspicuous interzonal midpiece $(I Z M)$ containing $M T s$ is at first wide and bulges slightly at the metaphase plate region. As the polar regions move farther apart, the IZM lengthens and decreases in diameter (Fig. 20). Although six anaphase nuclei from early-mid anaphase to late anaphase-early telophase were observed, no PRs were found. It is assumed that, as in Polysiphonia and Dasya, they remain split into their proximal and distal portions, which are difficult to observe. As the poles continue to move apart, the associated mitochondria become pushed against opposing regions of the cell membrane. The vacuoles reposition near the IZM and most likely coalesce (Fig. 21).

Telophase begins as the poles have finished moving apart. Chromosomes appear somewhat dispersed within a granulo-fibrillar (nucleolar?) material which is greatly restricted to each pole (Fig. 22). The vacuole(s) have moved between the two forming daughter nuclei and the NE eventually grows in, cutting off each new nucleus from the IZM. The NE 
at the polar areas also begins to reform at this time. Cleavage furrows, not seen until this late point in telophase, appear at the cell periphery. Many late telophases were observed, and, depending on the plane of sectioning, a large central vacuole and/or remnants of the IZM with associated PER are always found between the daughter nuclei (Figs. 23-25). In apical cells located slightly peripheral to a branch's longitudinal axis, the nuclei are not positioned at the cell ends. Instead the nuclei are situated diagonally in relation to the longitudinal cell axis (Figs. 23, 25). Likewise, cleavage furrows in these cells do not form perpendicular to the longitudinal axis but are angled relative to the nuclei. In contrast, Figure 2 shows a centrally located apical cell with nuclei located at the opposite ends of the cell, with a cleavage furrow just starting to form perpendicular to the cell's longitudinal axis. When apical cells on either side of the central-most cells are cleaved at an angle, the chain of new daughter cells forms an arc that eventually straightens, and the filament becomes aligned with the overall longitudinal plant axis. (Bouck, 1962, noted this phenomenon.)

Nuclear zones of exclusion are greatly diminished in the daughter cells. Unfortunately, the behavior of the PRs at this point was not determined; only one portion of a PR was found near a single daughter nucleus. The nuclei assume a more spherical shape and nucleoli reappear as the cleavage furrow deepens (Fig. 26). The large vacuole separating the daughter nuclei is bisected by the cleavage furrows and portions remain within each daughter cell. Before total partitioning occurs, a pit plug is formed in the narrow septum that connects the two cells. Figure 27 shows the beginning of plug formation as parallel ER cisternae associated with electron dense material transect the septum (see Aghajanian and 
Hommersand 1978, and Ramus 1969 for more details of pit plug formation). 


\section{Discussion}

In comparison to other electron microscopic studies of mitosis done in this laboratory, the present study on Lomentaria baileyana has been much more successful at yielding dividing cells in a short amount of time. About six months were actually spent sectioning branch tips, and over half of all apical and young cortical cells observed per tip were in some stage of division. While the majority were seen in prophase and late telophase-early interphase, 6 cells in prometaphase, 22 in metaphase, and 7 in anaphase were found.

The Rhodophyta is characterized to date by three basic types of mitosis: the Polysiphonia, Batrachospermum and Porphyridium types (Scott 1983). The Rhodymeniales is only the third florideophycean order in which a comprehensive ultrastructural study of cell division has been done. The Polysiphonia type of mitosis is conservative throughout the most advanced order, the Ceramiales, whereas Batrachospermum, the only florideophycean genus investigated outside of the Ceramiales, shows a fairly different type of mitosis. Lomentaria, although most closely resembling the Polysiphonia type, shows several unique features and displays some similarities to the Batrachospermum and Porphyridium types of mitosis.

In Lomentaria, the PRs are similar in structure and behavior to those observed in Apoglossum (Dave and Godward 1982), Membranoptera (McDonald 1972), Dasya (Phillips and Scott 1981) and Polysiphonia (Scott et al. 1980). The PRs of Lomentaria are similar in diameter (120-140 
$\mathrm{nm})$ to PRs found in Dasya and have a height $(40-60 \mathrm{~nm})$ quite similar to Polysiphonia PRs $(50-60 \mathrm{~nm})$. The prometaphase PRs of Lomentaria split into their proximal and distal halves as documented in the Ceramiales species, and by metaphase, PR halves appear separated by a distance similar to that in Dasya. Although polar rings were not seen in anaphase or telophase, it is probable that their proximal and distal portions remain split through telophase as documented in Dasya (Phillips and Scott 1981) and Polysiphonia (Scott et al. 1980).

The NEPs and associated heterochromatin beneath each PR in prophase Lomentaria cells are also found in Apoglossum, Dasya, Polysiphonia, and Membranoptera. Unlike the pronounced NEP in Apoglossum, Polysiphonia, and Membranoptera, only a slight elevation, similar to that in Dasya, is formed in Lomentaria. In all ceramialean genera studied, the NEPs do not form until late prophase. Scott et al. (1980) proposed a possible mechanism for NEP formation. The PRs, which are attached to the NE by fine electron dense struts, create a local tension on the NE as it begins to flatten at the polar regions. This local tension draws the NE, which initially provides little resistance, into a protrusion under each PR. In Lomentaria, however, the above mechanism most likely does not apply since NEPs can be found associated with the PRs during migration and even during interphase. Although fine electron dense struts are not seen in Lomentaria as in Polysiphonia and Dasya, some type of adhesive substance most probably exists to anchor the PRs to the NE. An alternative idea regarding NEP formation has been presented by Dave and Godward (1982) for mitosis in Apoglossum, but appears unfeasible in light of most other EM studies of NAO-NE interrelationships in lower plants and animals. 
The membranous structure projecting through the interphase, prophase and prometaphase polar rings is unique to Lomentaria. Seen in all transverse sections and in some longitudinal planes of section, it appears to be an extension of the outer nuclear membrane and a continuation of a smooth ER tubule. A somewhat similar juxtaposition of smooth ER to the PRs is seen in mid- to late interphase cells of Dasya. The smooth ER in Dasya, however, rests directly above the distal portion of the PR. and no membrane was ever seen extending through it. The functional significance of this organelle association in both Dasya and Lomentaria remains uncertain.

PER is present around the entire nucleus and over the polar regions from metaphase through telophase in all the florideophycean species studied, but is absent in the two investigated unicells Porphyridium (Schornstein and Scott 1980), and Flintiella (Scott in prep.). In Lomentaria, there is a well developed, extensive network of PER similar in amount to that found in Dasya. However, in contrast to these other florideiphycean species, PER in Lomentaria is always absent from the polar regions. Instead, mitochondria are seen at the metaphase and anaphase poles. It is possible that the polar mitochondrial aggregation could serve in place of a "capping" PER to function as a nuclear-cytoplasmic barrier. The isolation of dividing nuclei by membranous organelles would be expected of a multinucleated species, such as Lomentaria, where it may be necessary to separate division related activities from cytoplasmic, growth-related activities (Heath 1980, Phillips and Scott 1981). This specialized mitochondrial aggregation at the cytoplasm-nucleoplasm border has also been observed during mitosis in the unicellular red alga Flintiella, which, however, lacks PER (Scott in prep.). 
After the loss of the IZM at late telophase, a large stellate chloroplast functions to keep apart the newly formed nuclei in the bangiophycean algae Porphyridium and Flintiella. In Lomentaria, as in all the florideophycean species studied, a large central vacuole helps to ensure that each daughter cell receives a single nucleus following cytokinesis. In Membranoptera, Polysiphonia and Dasya, vacuole formation begins at about the same time as interzonal spindle elongation, whereas in Batrachospermum, a large vacuole is almost fully formed before mitosis. Vacuole formation in Lomentaria begins slightly earlier (late prometaphase to metaphase) than in the Ceramiales species but vacuoles are not fully formed until interzonal spindle elongation.

The prometaphase events in Lomentaria have not been observed before in a red alga. In Apoglossum, Membranoptera, Polysiphonia and Dasya, the NE becomes fenestrated at the poles in late prometaphase as MTs become evident in the nucleus. In Porphyridium, a single invagination, devoid of MTs, ruptures and leaves a wide gap in the NE under each NAO. Both Batrachospermum and Flintiella form invaginations on the sides of their NAOs which develop into channels containing NE-bound MTs. The channels transect the nucleus before breaking down, again leaving a single gap at each pole. The pockets that appear to the sides of a PR in Figures 9-12 suggest that Lomentaria, like Batrachospermum, forms an invagination to two sides of each PR. The localized growth of NE that forms the pockets in Lomentaria appears largely pore-free in contrast to the surrounding NE with an abundance of nuclear pores. The NE pocket stops at a depth similar to that seen in Porphyridium and subsequently ruptures. Portions of the NE seen both reflexed against the inner nuclear membrane and free in the nucleoplasm during prometaphase are not evident 
by metaphase, but one fragment of NE usually remains between the two gaps. This fragment was seen in at least a few planes of section in all metaphase and anaphase nuclei, and positioned directly above it, when observed, were the disjoined PRs. Unlike Batrachospermum where all the NE between the two channels breaks down leaving one wide gap, this central NE fragment between the two invaginations appears persistent in Lomentaria. The two initially small gaps most likely enlarge irregularly to cover a large portion of the polar region. This is revealed in a series of thin sections as a polar region with one gap, two gaps separated by a central NE fragment, or less frequently as one or two gaps with other small NE pieces.

Nuclear envelope pocket formation and rupture is seen in some fungi (Heath et al. 1979, McNitt 1973, Powell 1980, Whisler and Travland 1973) and in a brown alga (Markey and Wilce 1975). Three chytrid fungi, Harpochytrium (Whisler and Travland 1973), Phylctochytrium irregulare (McNitt 1973), Rhizophydium spherotheca (Powell 1980) and the brown alga Pylaiella littoralis (Markey and Wilce 1975) similarly display spindle incursions where a single pocket with MTs forms directly below the NAOs (centrioles) at late prophase. It seems probable that growing MTs exert a force on the NE resulting in the initial formation of pockets. Subsequent rupture creates polar gaps through which MTs enter the nucleus (Fuller 1976, Heath 1978). This mechanism of pocket formation does not occur in the hemiascomycete Taphrina (Heath et al. 1979), nor in the red algae Porphy-

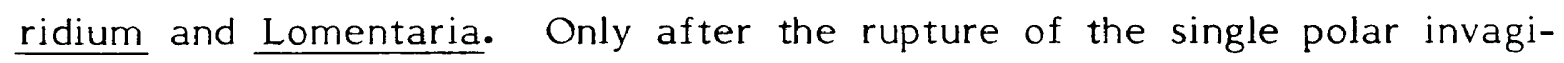
nation of Taphrina and Porphyridium were MTs seen in this region, apparently entering the nucleus. The paired pockets at the poles of Lomentaria also initially lack MTs, although it should be noted that the presence 
of MTs could have been missed since only one cell was observed at this stage of mitosis. Unlike Taphrina and Porphyridium, MTs do not sharply converge at the poles. Instead, they terminate broadly at the junction of cytoplasm and nucleoplasm. Most likely, spindle MTs in Lomentaria are derived from the inner region of this boundary as in other higher red algae, and therefore are not of extranuclear origin. The function of the large gaps in this genus and the smaller, more numerous fenestrations in the Ceramiales species is not conclusively known. However, it is quite feasible that these two types of relatively large polar interruptions of the NE might allow spindle precursor material to enter the prometaphase nucleus at a faster rate than entrance through the much smaller nuclear pores would permit.

This investigation of a species within an advanced order outside the Ceramiales shows some noteworthy variations on the basic Polysiphonia type of mitosis, the most significant of which are the polar events at prometaphase. The initial formation of NE pockets on two sides of the PRs is similar to that seen in Batrachospermum, but the invaginations rupture at a shallow depth instead of penetrating from pole to pole. Neither one large gap as seen in Batrachospermum nor small fenestrations of the $\mathrm{NE}$ as in the Ceramiales exists. Instead, a relatively large fragment of $\mathrm{NE}$ between, and small fragments within, two moderate sized gaps characterize the prometaphase poles of Lomentaria. Based on these observations, mitosis in Lomentaria may represent an evolutionary intermediate between that seen in the species of th; e most advanced florideophycean order, the Ceramiales, and the genus Batrachospermum from the more primitive florideophycean order, the Nemaliales. This would be consistent with the taxonomic placement of Lomentaria within the Rhodymeniales, 
the second most advanced order of the Florideophyceae.

It would be beneficial now to examine mitosis within the other families of the Rhodymeniales, as was originally attempted in the study, to see if shallow prometaphase NE invaginations, subsequent formation of two gaps at each pole, and the absence of polar PER are ubiquitous characteristics of this order. As more mitotic studies of red algae are completed, it is hoped that the minor variations such as found here between closely related orders, in addition to the more obvious differences seen between members of more distantly related groups, may prove to be taxonomically useful criteria in red algal classification. 


\section{Literature Cited}

Aghajanian, J. G., Hommersand, M. H. 1978. The fine structure of the pit connections of Batrachospermum sirodotii Skuja. Protoplasma 96: $247-265$.

Bajer, A. 1973. Interaction of microtubules and the mechanism of chromosome movement (zipper hypothesis). I. General principle. Cybobios $8: 139-160$.

Bager, A., Mole-Bager, J. 1972. Spindle dynamics and chromosome movements. Int. Rev. Cytol. Suppl. 34: 1-271.

Bold, H. B., Wynne, M. W. 1978. Introduction to the Algae. Structure and Reproduction. Englewood Cliffs, N.J., Prentice-Hall, Inc.

Bouck, G. B. 1962. Chromatophore development, pits, and other fine structure in the red alga, Lomentaria baileyana (Harv.) Farlow. J. Cell Biol. 12: 553-569.

Dave, A. J., Godward, M. B. E. 1982. Ultrastructural studies in the Rhodophyta. I. Development of mitotic spindle poles in Apoglossum ruscifolium, Kylin. J. Cell Sci. 58: 345-362.

Dixon, P. S. 1973. Biology of the Rhodophyta. New York, N.Y. Hafner Press.

Duckett, J. G., Peel, M. C. 1978. The role of transmission electron microscopy in elucidating the taxonomy and phylogeny of the Rhodophyta. In: Modern Approaches to the Taxonomy of the Red and Brown Algae. (Irvine, D. E. G., Price, J. H. eds.) pp. 157-204. New York, N.Y., Academic Press.

Fuge, H. 1974. Ultrastructure and function of the spindle apparatus, microtubules and chromosomes during nuclear division. Protoplasma 82: $289-320$.

Fuller, M.S. 1976. Mitosis in fungi. Int. Rev. Cyt. 45: 113-153.

Hara, Y., Chihara, M. 1974. Comparative studies on the chloroplast ultrastructure in the Rhodophyta with special reference to their taxonomic significance. The Science Reports of the Tokyo Kyoiku Daigaku 15(232): 209-235.

Heath, I. B. 1978. Experimental studies of mitosis in the fungi. In: Nuclear Division in the Fungi. (Heath, I. B., ed.) pp. 89-176. New York, N.Y. Academic Press. 
Heath, I. B. 1980a. Fungal mitosis, the significance of variations on a theme. Mycologia 72: 229-250.

Heath, I. B. 1980b. Variant mitoses in lower eukaryotes: indicators of the evolution of mitosis? Intern. Rev. Cytol. 64: 1-80.

Heath, I. B. 1981. Mitosis through the Electron Microscope. In: Mitosis/ Cytokinesis. (Zimmerman, A. M., ed.) pp. 245-275. New York, N.Y. Academic Press.

Heath, I. B., Ashton, M. L., Rethornet, K., Heath, M. C. 1983. Mitosis and the phylogeny of Taphrina. Can J. Bot. 60: 1696-1725.

Hepler, P. K. 1980. Membranes in the mitotic apparatus of barley cells. J. Cell Biol. 86: 490-499.

Inoue, S., Ritter, H. Jr. 1975. Dynamics of mitotic spindle organization and function. In: Molecules and Cell Movement. (Inoue, S., Stephens, P. E., eds.) Pp. 3-30. New York, N.Y. Raven Press.

Jackson, W. T., Doyle, B. G. 1982. Membrane distribution in dividing endosperm cells of Haemanthus. J. Cell Biol. 94: 637-643.

Kubai, D. F. 1978. Mitosis and fungal phylogeny. In: Nuclear Division in the Fungi. (Heath, B., ed.) pp. 177-224. New York, N.Y. Academic Press.

Leedale, G. F. 1970. Phylogenetic aspects of nuclear cytology in the algae. In: Phylogenesis and Morphorgenesis in the Algae. (J. F. Frederick and R. M. Klein eds.) pp 429-453. New York, N.Y. Ann. N.Y. Acad. Sci. 175.

Luykx, P. 1970. Cellular mechanisms of chromosome distribution. Int. Rev. Cytol. Suppl. 2: 1-173.

Markey, D. R., Wilce, R. T. 1975. The ultrastructure of reproduction in the brown alga Pylaiella littoralis. I. Mitosis and cytokinesis in the plurilocular gametangia. Protoplasma 85: 219-241.

McDonald, K. 1972. The ultrastructure of mitosis in the marine red alga Membranoptera platyphylla. J. Phycol. 8: 156-166.

McDonald, K., Pickett-Heaps, J. D., McIntosh, J. R., Tippit, D. H. 1977. On the mechanism of anaphase spindle elongation in Diatoma vulgare. J. Cell Biol. 74: 377-388.

McNitt, R. 1973. Mitosis in Phlyctochytrium irregulare. Can. J. Bot. 51: 2065-2074.

Oakley, B. R. 1978. Some advantages and limitations of mitosis as a phylogenetic criterion. BioSystems 10: 59-64. 
Phillips, D., Scott, J. 1981. Ultrastructure of cell division and reproductive differentiation of male plants in the Florideophyceae (Rhodophyta). Mitosis in Dasya baillouviana. Protoplasma 106: 329-341.

Pickett-Heaps, J. D. 1969. The evolution of the mitotic apparatus: an attempt at comparative ultrastructural cytology in dividing plant cells. Cytobios 3: 257-280.

Pickett-Heaps, J. D. 1974. The evolution of mitosis and the eukaryotic condition. BioSystems 6: 37-48.

Pickett-Heaps, J. D. 1975a. Green Algae. Structure, Reproduction and Evolution in Selected Genera. Sunderland, Mass. Sinauer Associates, Inc.

Picket-Heaps, J. D. 1975b. Aspects of spindle evolution. Ann. N.Y. Acad. Sci. 253: 352-361.

Pickett-Heaps, J. D., Tippit, D. H. 1978. The diatom spindle in perspective. Cell 14: 455-467.

Powell, M. J. 1980. Mitosis in the aquatic fungus Rhizophydium spheratheca (Chytridiales). Amer. J. Bot. 67: 839-853.

Pueschel, C. M. 1980. A reappraisal of the cytochemical properties of rhodophycean pit plugs. Phycologia 19: 210-217.

Pueschel, C. M., Cole, K. M. 1982. Rhodophycean pit plugs: and ultrastructural survey with taxonomic implications. Amer. J. Bot. 69: 703-720.

Ramus, J. 1969. Pit connection formation in the red alga Pseudogloiophloea. J. Phycol. 5: 57-63.

Schornstein, K. L., Scott, J. 1982. Ultrastructure of cell division in the unicellular red alga Porphyridium purpureum. Can. J. Bot. 60: 85-97.

Scott, J. 1983. Mitosis in the freshwater red alga Batrachospermum ectocarpum. Protoplasma 118: 56-70.

Scott, J. 1984. Electron microscopic contributions to red algal phylogeny. J. Phycol. Suppl. 20: 6(a).

Scott, J., Bosco, C., Schornstein, K., Thomas, J. 1980. Ultrastructure of cell division and reproductive differentiation of male plants in the Florideophyceae (Rhodophyta). Cell division in Polysiphonia. J. Phycol. 16: 507-524.

Stewart, K. D., Mattox, K. R. 1975. Comparative cytology, evolution and classification of the green algae with some considerations of the origin of other organisms with chlorophylls a and b. Bot. Rev. 41: $104-135$. 
von Stosch, H. A. 1964. Wirkungen von Jod und Arsenit auf Meeresalgen in Kultur. Proc. Intern, Seaweed Symp. 4: 142-150.

Whisler, H. C., Travland, L. B. 1973. Mitosis in Harpochytrium. Arch. Protistenkd. 115: 69-74. 


\title{
Key to Abbreviations
}

\author{
Nucleus.....N \\ Nucleolus......No
}

Vacuole.....V 


\section{Plate I}

Figure 1 Longitudinal thick section through tip of vegetative branch. Bright field optics. $\times 560$

Figure 2 Thin section of the central most tip region. One apical cell (arrow) is in late telophase. Pit connections are seen between many of the cells comprising the vegetative axis (arrowheads). $\times 2800$

Figure 3 Early prophase nucleus with migrating polar rings (PRs). One PR is visible in this section (arrowhead) and the location of the other is marked by an asterisk. $\times 15,000$

Figure 4 Different section of same nucleus as figure 3 showing other PR (arrow) and the position of the first PR (asterisk). x15,000

Figure 5 Longitudinal view of a prophase PR. Note the slight, pore free nuclear envelope protrusion (NEP) and small cytoplasmic zone of exclusion with associated microtubules (MTs). The outer membrane of the nuclear envelope (NE) appears to extend through the PR. A small amount of heterochromatin is present beneath the NE elevation. Nucleus (N). $\times 52,500$

Figure 6 Transverse section of a prophase PR (arrowhead) with enclosed tubular extension from the NE. Nuclear pores are visible to one side of the PR. $\times 52,500$ 


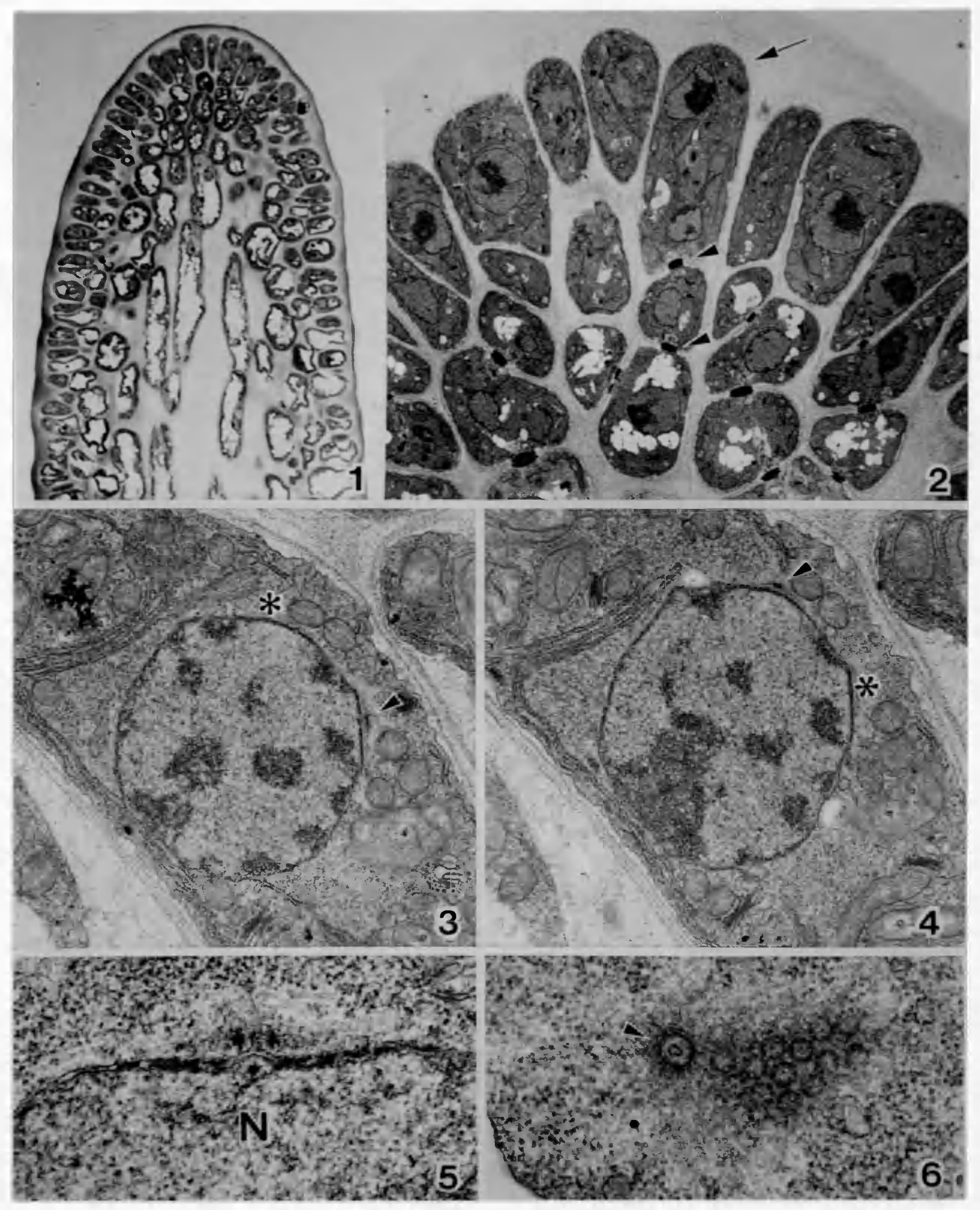




\section{Plate II}

Figure 7 Prophase nucleus with PRs (arrowheads) in a later stage of migration than shown in Figs. 3 and 4. Note the smooth surfaced $N E$ region beneath and the tubular extension of NE outer membrane through the center of each PR. Nucleolus (No). $\times 27,000$

Figure $8 \quad$ Early prometaphase oval nucleus with flattened polar regions. One PR with associated NEP is present (arrowhead) while an asterisk marks the location of the other PR seen in adjacent sections. The nucleolus has become less compact and perinuclear endoplasmic reticulum (PER) has begun accumulating. $\times 22,500$ 


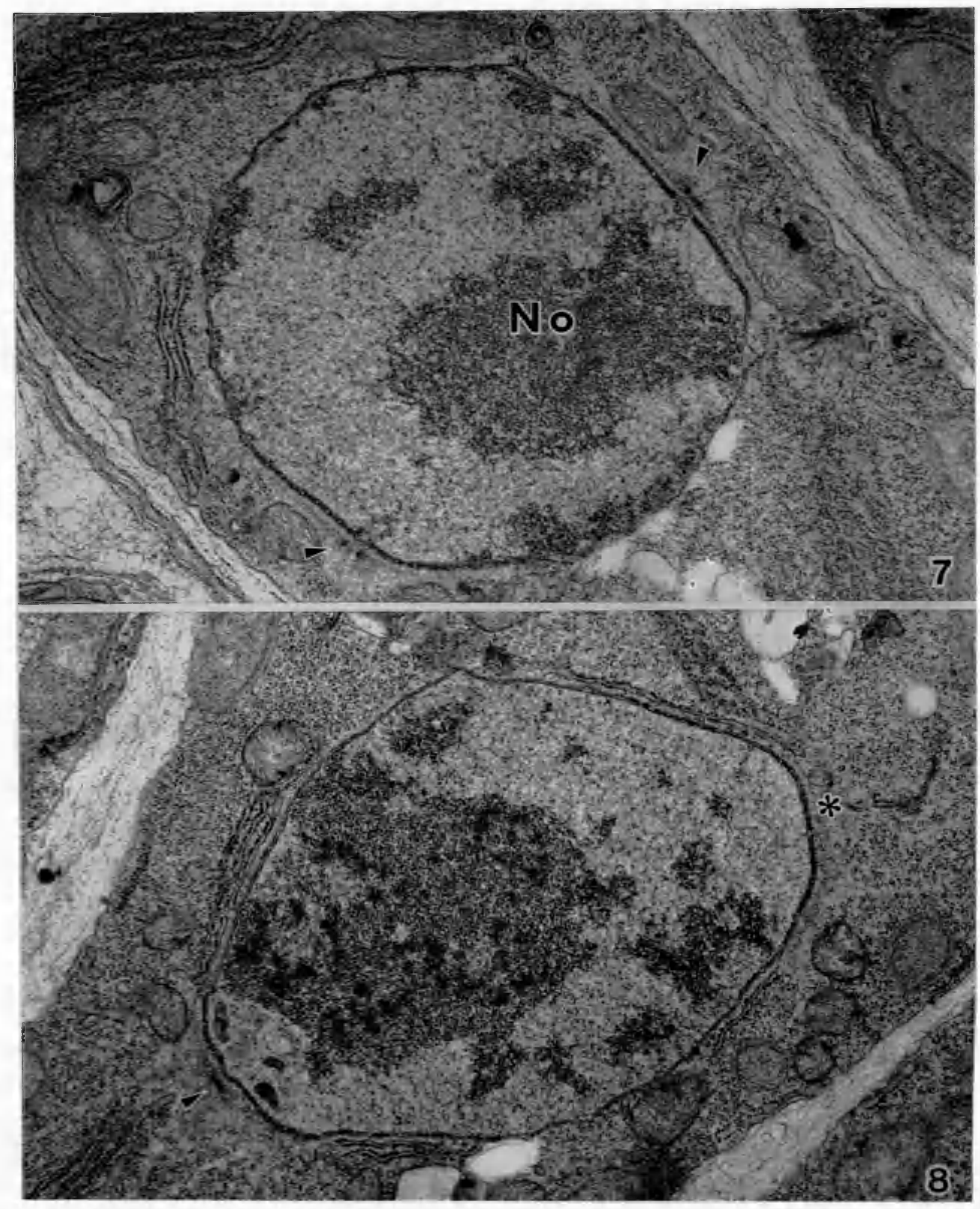




\section{Plate III}

Figures 9-12 Consecutive sections of a prometaphase division pole with $\mathrm{NE}$ invaginations.

Figure 9 Note the invagination of the NE. The location of the PR, seen in adjacent sections (Figs. 11, 12), is marked by an arrow. An arrowhead indicates the location of a second invagination seen in Figs. 11 and 12. x25,000

Figure 10 A somewhat tangential plane of section through the same invagination. $\times 25,000$

Figure 11 The PR is present (arrow) with a second invagination of the NE evident. The location of the first invagination seen in Figs. 9 and 10 is marked by an arrowhead. $\times 25,000$

Figure 12 Another plane of section through the invagination in Fig. 11. Location of first invagination marked by arrowhead. $\times 25,000$

Figure 13 Early prometaphase nucleus sectioned through polar regions with an apparently intact NE invagination. Compare with Fig. 14. x16,500

Figure 14 Adjacent section to Fig. 13 showing that the invagination has actually ruptured at a shallow depth. $x 16,500$ 

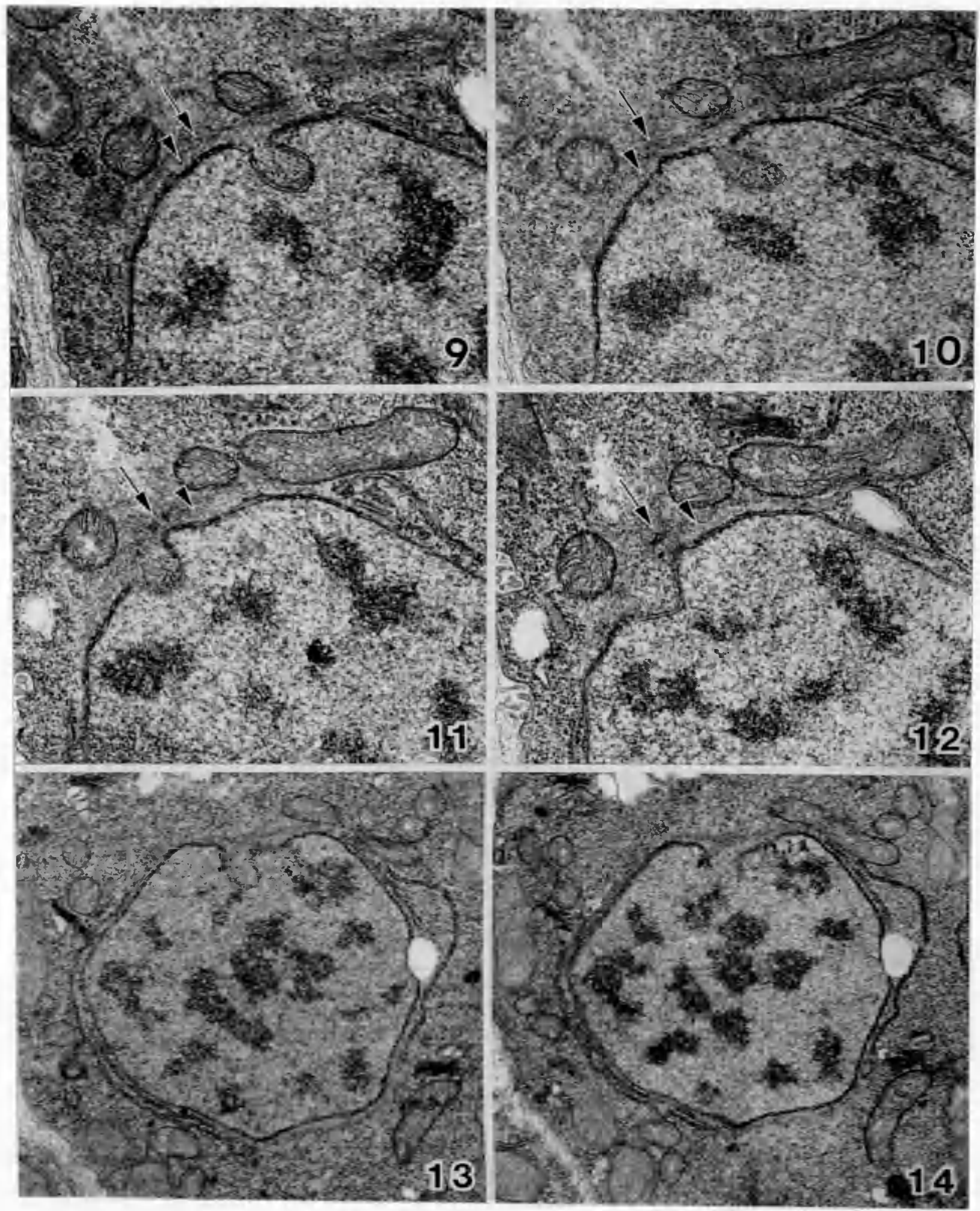


\section{Plate IV}

Figure 15 A mid-prometaphase pole with a ruptured invagination to one side of the PR. The PR has separated slightly into its proximal and distal portions (arrowheads indicate the proximal and distal portions as seen on just one side of the longitudinally sectioned PR). Note the extension of the NE outer membrane through the $\mathrm{PR}$ and the small break in the NE to the other side of the PR. $\times 35,000$

Figure 16 Another mid-prometaphase nucleus with a ruptured invagination. A slightly tangential view of the PR (arrowhead) which has split into proximal and distal portions is present. $\times 28,000$

Figure 17 Elongated late prometaphase nucleus. Note mitochondria which have begun to gather at the poles and the presence of PER. $x 18,000$

Figure 18 Another late prometaphase nucleus. Remnants of the nucleolus are seen against the NE. Note the NE fragments at gap regions of the poles. $\times 15,000$ 


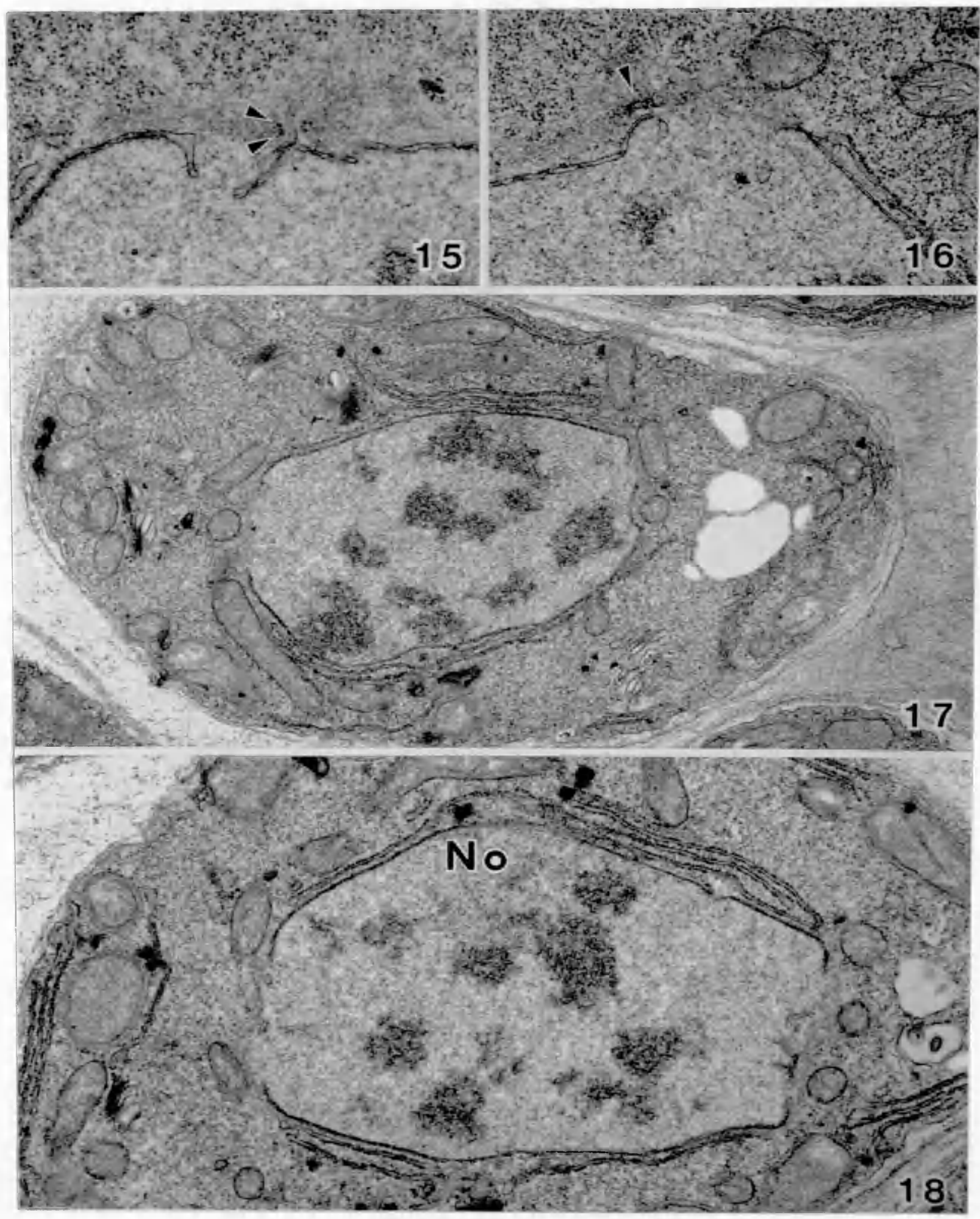




\section{Plate V}

Figure 19 Longitudinal section through metaphase nucleus. A persistent centrally located region of NE (arrowheads) is present at both poles. MTs converge broadly at the poles; kinetochores are not clearly seen. $\times 28,000$

Figure 20 Mid anaphase nucleus with an elongated interzonal midpiece (IZM). The chromosomes with associated nucleolar material (arrowheads) have already reached the poles. Two kinetochores are seen (arrows). x21,200 


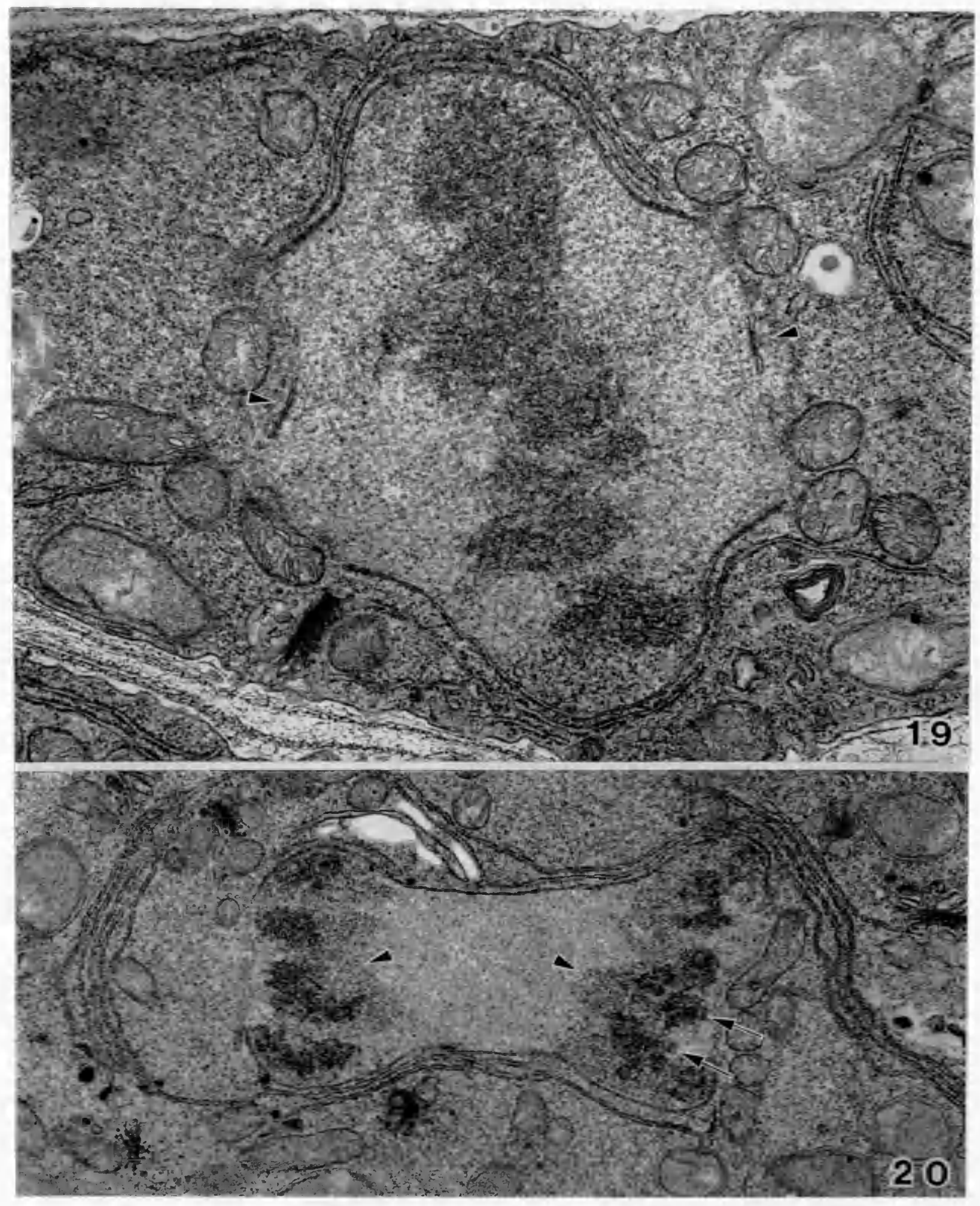




\section{Plate VI}

Figure 21 Late anaphase. The poles have moved farther apart and the nucleus stretches from one side of the cell to the other. A vacuole $(V)$ is present at the IZM region. $\times 15,000$

Figure 22 Late anaphase. Note the persistent region of NE (arrowhead). The chromosomes have begun to disperse (arrows). $\times 28,500$

Figure 23 Late telophase. Daughter nuclei are separated by a vacuole, PER, and remnants of the IZM (asterick). A cleavage furrow (arrowhead) is beginning to form on one side of the cell. $\mathrm{x} 16,500$ 


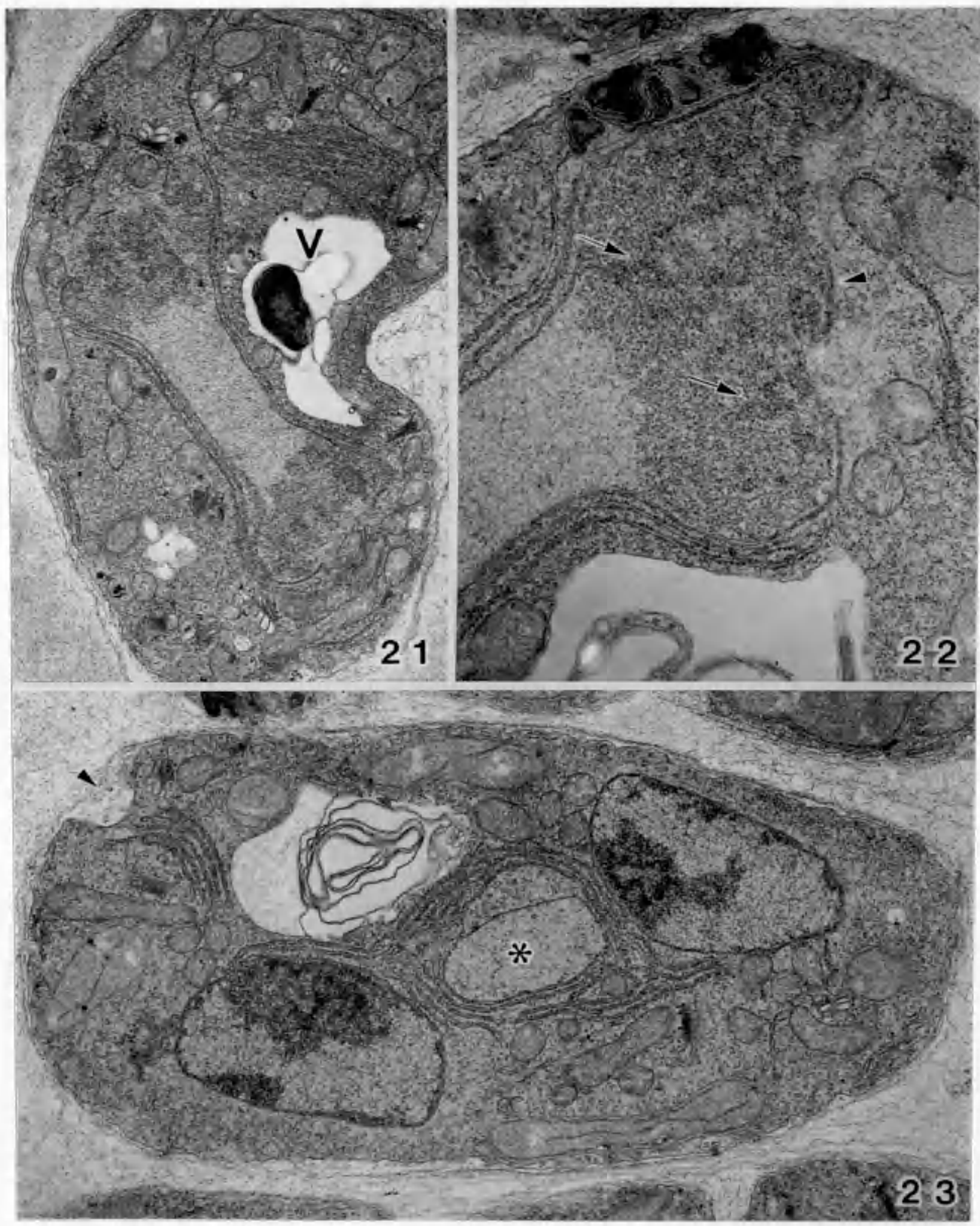




\section{Plate VII}

Figure 24 Late telophase. Nuclei are separated by a vacuole. Cleavage furrow (arrowhead) is evident on one side of the cell. x11,800

Figure 25 Late telophase. Nuclei are situated diagonally in relation to the longitudinal cell axis. The central vacuole is not evident in this plane of sectioning. $\times 16,500$

Figure 26 Cytokinesis. The cleavage furrow has almost separated the cell. Remnants of the vacuole can be seen in one cell. $\times 16,500$

Figure 27 Early stages of pit plug formation. Electron dense material and associated ER traverse the septum. $\times 26,000$ 


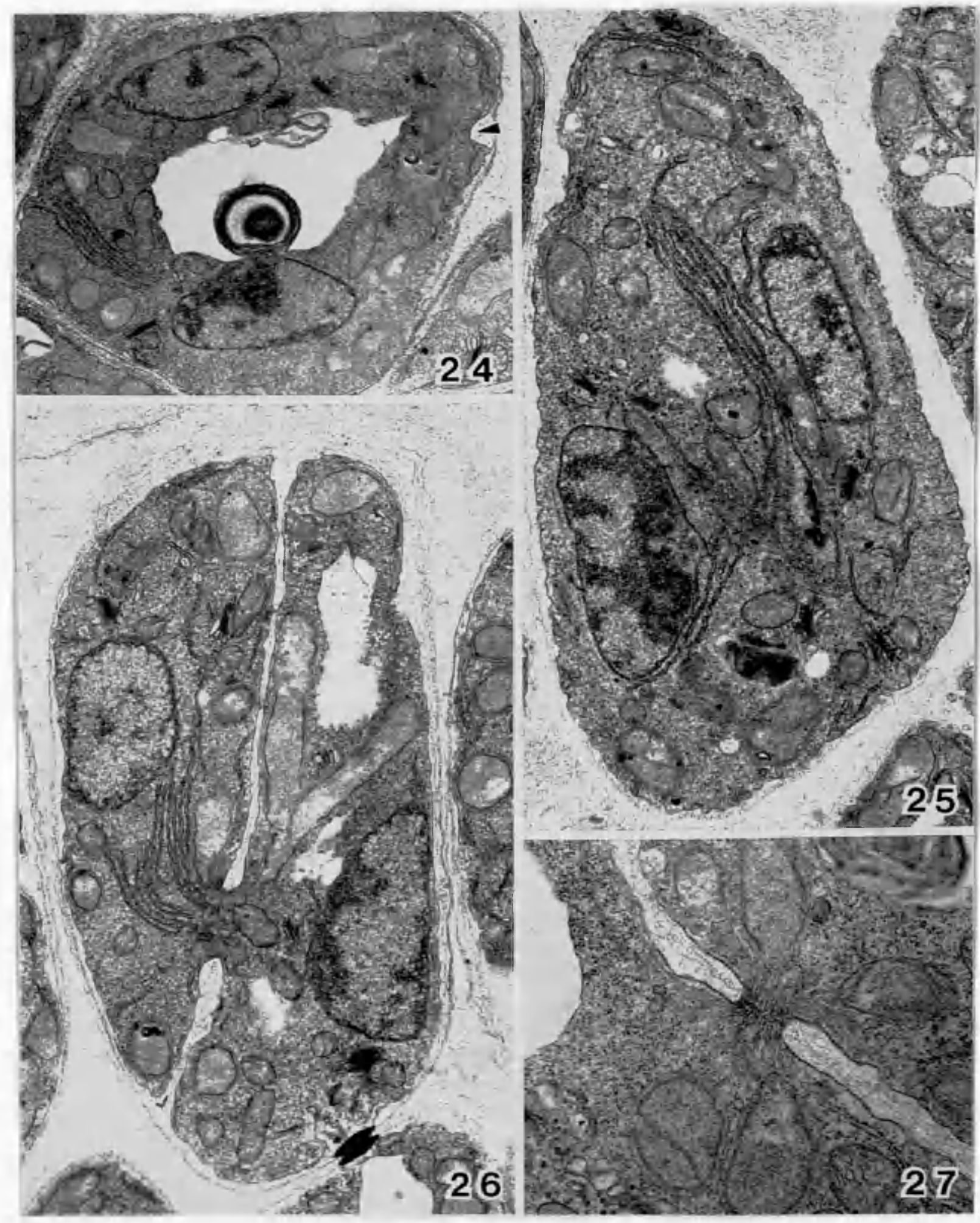




\section{Vita}

\section{Elizabeth Carpenter Davis}

Born in Richmond, Virginia, December 12, 1961. Graduated from St. Annes-Belfield School in Charlottesville, June, 1979. B.S. in Biology from the College of William and Mary, Williamsburg, Virginia, May 1983. Teaching assistantship and candidate for M.A. in biology at the College of William and Mary 1983-1984. 